\title{
KEAMANAN CITRA DENGAN WATERMARKING MENGGUNAKAN PENGEMBANGAN ALGORITMA LEAST SIGNIFICANT BIT
}

\author{
Kurniawan ${ }^{1}$, Indah Agustien Siradjuddin ${ }^{2}$, Arif Muntasa ${ }^{3}$ \\ ${ }^{1,2,3}$ Program Studi Teknik Informatika, Universitas Truonojoyo Madura \\ Jl. Raya Telang, PO BOX 2, Kamal, Bangkalan-69162, Indonesia \\ Email: ndoro.awank@gmail.com ${ }^{1}$, indah.agustien@if.trunojoyo.ac.id ${ }^{2}$, arifmuntasa@gmail.com ${ }^{3}$
}

\begin{abstract}
Abstrak: Image security adalah proses mengamankan data digital yang berbentuk citra. Salah satu metode pengamanan data citra digital adalah watermarking menggunakan algoritma Least Significant Bit atau LSB. Konsep kerja image security menggunakan algoritma $L S B$ adalah dengan mengganti nilai bit citra pada lokasi tertentu sehingga membentuk pola. Pola hasil dari pergantian nilai bit pada citra inilah yang disebut dengan tanda air atau watermark. Pemberian watermark pada citra menggunakan algoritma LSB memiliki konsep sederhana sehingga informasi yang disisipkan akan mudah hilang saat mengalami serangan seperti serangan noise atau kompresi. Sehingga perlu dilakukan modifikasi yaitu pengembangan algoritma $L S B$. Hal ini dilakukan untuk mengurangi distorsi informasi watermark terhadap serangan yang terjadi. Dalam penelitian ini dibagi menjadi 6 proses, yaitu ekstraksi kanal warna citra cover, pencarian area busy, penyisipan watermark, perhitungan akurasi penyisipan, ekstraksi watermark dan perhitungan akurasi ekstraksi. Ekstraksi kanal warna citra cover adalah proses mendapatkan kanal warna biru pada citra cover. Informasi watermark akan disisipkan pada area busy atau sibuk dengan mencari area yang memiliki unsur terbanyak pada citra cover. Selanjutnya citra watermark disisipkan ke dalam citra cover sehingga menghasilkan citra terwatermark menggunakan algoritma beberapa pengembangan LSB dan mencari akurasinya dengan menghitung nilai Peak Signal to Noise Ratio. Sebelum citra terwatermark diekstraksi, dilakukan pengujian dengan memberi noise dan melakukan kompresi format jpg. Akurasi hasil ekstraksi dicari dengan menghitung nilai Bit Error Rate.
\end{abstract}

Kata kunci: Image Security; Watermarking; Least Significant Bit; Pengembangan Algoritma LSB.

\begin{abstract}
Image security is a process to save digital. One method of securing image digital is watermarking using Least Significant Bit algorithm. Main concept of image security using LSB algorithm is to replace bit value of image at specific location so that created pattern. The pattern result of replacing the bit value of image is called by watermark. Giving watermark at image digital using LSB algorithm has simple concept so that the information which is embedded will lost easily when attacked such as noise attack or compression. So need modification like development of LSB algorithm. This is done to decrease distortion of watermark information against those attacks. In this research is divided by 6 process which are color extraction of cover image, busy area search, watermark embed, count the accuracy of watermark embed, watermark extraction, and count the accuracy of watermark extraction. Color extraction of cover image is process to get blue color component from cover image. Watermark information will embed at busy area by search the area which has the greatest number of unsure from cover image. Then watermark image is embedded into cover image so that produce watermarked image using some development of LSB algorithm and search the accuracy by count the Peak Signal to Noise Ratio value. Before the watermarked image is extracted, need to test by giving noise and doing compression into jpg format. The accuracy of extraction result is searched by count the Bit Error Rate value.
\end{abstract}

Keywords: Image Security, Watermarking, Least Significant Bit, Development of LSB Algorithm.

\section{PENDAHULUAN}

Internet saat ini bukan lagi menjadi alat pendukung yang dapat membantu pekerjaan manusia, bahkan sebagian orang menjadikan internet sebagai kebutuhan utama dalam hidupnya. Fungsinya yang sangat banyak menjadikan alasan para pengguna tidak bisa lepas dari internet. Selain sebagai media pencarian informasi, media social dan media pembelajar- an, kebanyakan orang memanfaatkan internet sebagai media utama pengiriman data digital dari tempat satu ke tempat yang lain bahkan lintas negara. Perpindahan data dibuat sangat mudah dan cepat dengan internet.

Apabila dilihat dari fungsinya, data dapat dibagi menjadi tiga yaitu public, private dan protected. Public menunjukkan bahwa data tersebut bersifat untuk umum, private menunjukkan bahwa data 
tersebut bersifat pribadi dan protected ialah data yang bersifat dilindungi. Data yang bersifat private biasanya si pemilik tidak ingin data tersebut dilihat oleh orang lain sehingga disimpan secara pribadi. Sedangkan data protected biasanya dikhususkan untuk data yang bersifat penting sehingga keamanannya sangat diperhatikan. Berdasarkan sifat-safat tersebut, muncul penilitian terkait keamanan data. Penelitian ini bertujuan untuk mencari bagaimana cara melindungi data dari segala kemungkinan manipulasi atau kerusakan yang terjadi.

Watermarking adalah teknik yang digunakan untuk menyisipkan informasi pada media multimedia dengan tujuan memberi tanda kepemilikan atau menjaga keaslian data tetapi tidak diketahui keberadaannya oleh indera manusia. Watermarking dapat dimanfaatkan pada media digital seperti data text, citra, audio dan video. Dalam penelitian Tugas Akhir ini akan mengulas salah satu metode watermarking pada citra yaitu Least Significant Bit (LSB). Penulis juga melakukan penggabungan metode enkripsi hamming code dan repetition code yang bertujuan untuk memperbaiki kekurangan dari metode classic dari $L S B$. Hasil dari penggabungan metode-metode tersebut dinamakan pengembangan Least Significant Bit.

\section{WATERMARKING}

Watermarking adalah kumpulan bit pola atau informasi yang disisipkan pada citra digital, audio atau video yang menunjukkan kepemilikan, kebenaran dan lain sebagainya [1]. Disamping itu watermarking digunakan untuk menjaga kebsahan atau melindungi data. Walau bagaimanapun, watermarking harus tak terlihat kehadirannya pada citra yang disisipi watermark [2]. Dan juga watermarking harus cukup tahan (robust) terhadap dari segala perubahan yang bertujuan menghilangkan informasi watermark seperti penambahan noise dan lain sebagainya [3].

Pada citra digital, informasi dapat disisipkan secara langsung ke dalam setiap bit citra atau pada area tertentu sehingga dapat menyembunyikan informasi pada citra [4]. Least Significant Bit (LSB) adalah salah satu metode penyisipan watermark pada citra dengan cara mengganti nilai pada bit tertentu citra. Citra watermark berbentuk citra biner disisipkan pada citra berwarna atau citra $R G B$. Agar watermark tidak tampak pada citra yang akan disisipkan watermark, komponen yang akan diubah nilai pikselnya adalah salah satu dari komponen $R G B$ tersebut.

Setiap komponen citra $R G B$, nilai piksel pada citra memiliki rentang nilai $0-255$ atau 8 bit. Prinsip penyisipan pada Algoritma $L S B$ yaitu dengan mengganti nilai biner ke- $n$ menjadi nilai watermark. Jika nilai piksel pada citra adalah 138 maka jika dilakukan konversi ke biner menjadi 10000110 dan semisal nilai watermark yang disisipkan adalah 1. Maka nilai piksel tersebut akan menjadi 10000111 atau 139 dalam bentuk decimal. Metode hybrid atau gabungan yang digunakan pada penelitian ini adalah $L S B$ with Hamming Code dan LSB with Repetition Code. Gambar 1a dan 1b menunjukkan alur kerja sistem secara umum.

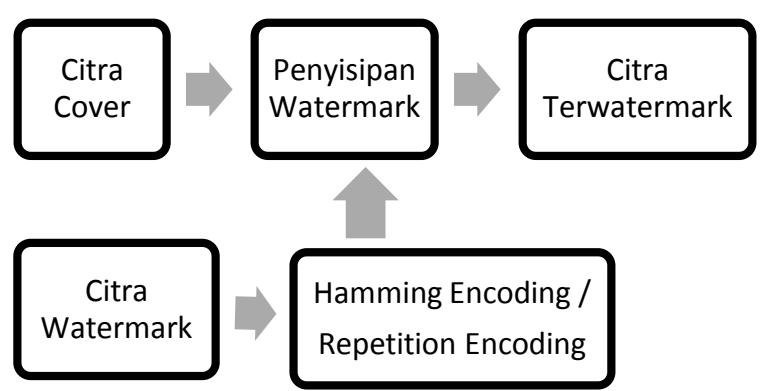

Gambar 1a. Proses Penyisipan Watermark

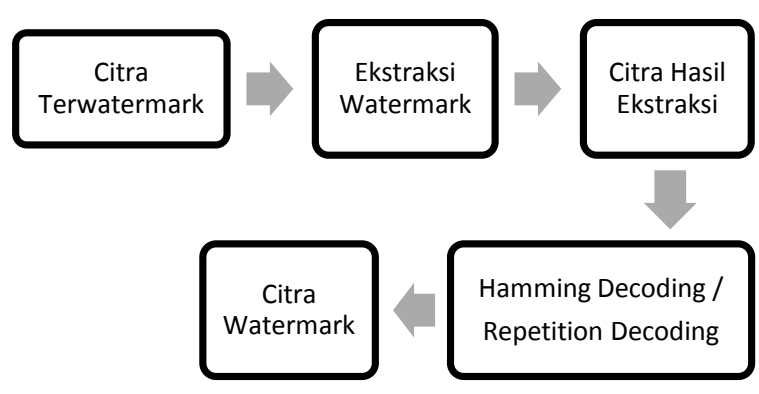

Gambar 1b. Proses Ekstraksi Watermark

\section{Penentuan Area Sibuk}

Area sibuk atau busy pada penelitian ini ditentukan dengan cara menghitung jumlah ragam objek. Ragam objek diperoleh dengan proses labeling. Proses labeling adalah proses membaca nilai 1 pada citra biner dan memberi dengan nilai 1 sampai $n$ dengan aturan ketetanggaan. Namun sebelum proses labeling, citra dilakukan operasi splitting atau pembagian menjadi blok-blok kecil seukuran citra watermark. Blok citra yang memiliki ragam atau label terbanyak, maka blok tersebut dinyatakan sebagai lokasi sibuk atau busy dan tempat citra watermark disisipkan. Dalam pelabelan menggunakan aturan 4 atau 8 obyek yang terhubung. Sebagai contoh labeling 4 connected dan labeling 8 connected dapat dilihat pada Gambar 2a dan 2b.

\section{Hamming Code}

Hamming code adalah salah satu enkripsi yang sering digunakan dalam keamanan text. Dalam $(n, k)$ Hamming code dimana $k$ adalah jumlah bit pesan, $n$ adalah jumlah bit yang berkorespodensi hasil enkripsi 
dengan $n>k$ dan (n-k) adalah jumlah cek bit [8]. Hamming code dapat dirumuskan seperti berikut:

$\mathrm{n}=2^{\mathrm{m}}-1$

$\mathrm{k}=2^{\mathrm{m}}-1-\mathrm{m}$

Dimana $m=2,3,4, \ldots$

Jika $\mathrm{m}=3$ maka berkoresponden dengan kode $(7,4)$ hamming code. Hamming code secara umum tersusun dari matrik parity dan matrik identitas. Dalam kasus $(7,4)$ hamming code dapat dilihat pada Gambar 3.

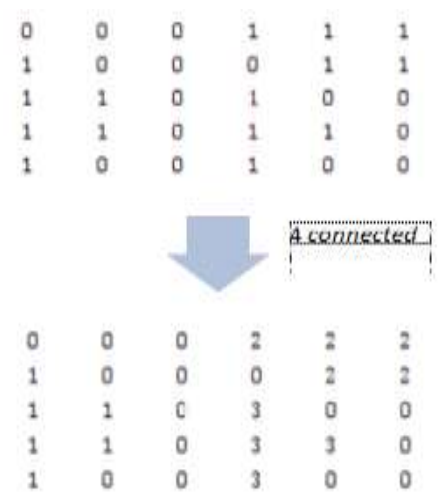

Gambar 2a. Contoh Labeling 4 Connected

$\begin{array}{llllll}0 & 0 & 0 & 1 & 1 & 1 \\ 1 & 0 & 0 & 0 & 1 & 1 \\ 1 & 1 & 0 & 1 & 0 & 0 \\ 1 & 1 & 0 & 1 & 1 & 0 \\ 1 & 0 & 0 & 1 & 0 & 0\end{array}$

$\begin{array}{llllll}0 & 0 & 0 & 2 & 2 & 2 \\ 1 & 0 & 0 & 0 & 2 & 2 \\ 1 & 1 & 0 & 2 & 0 & 0 \\ 1 & 1 & 0 & 2 & 2 & 0 \\ 1 & 0 & 0 & 2 & 0 & 0\end{array}$

Gambar 2b. Contoh Labeling 8 Connected

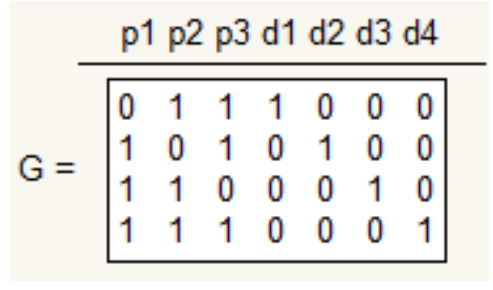

Gambar 3. Matrik $(7,4)$ Hamming code

Dengan aturan:

$p l=d 2 \oplus d 3 \oplus d 4$

$p 2=d 1 \oplus d 3 \oplus d 4$

$p 3=d 1 \oplus d 2 \oplus d 4$

$\bigoplus$ adalah operasi logika XOR

d1, d2, d3 dan d4 merupakan matrik identitas
Sehingga hasil enkripsi nilai 1010 menggunakan $(7,4)$ hamming code dapat dilihat pada Gambar $4 \mathrm{di}$ bawah ini.

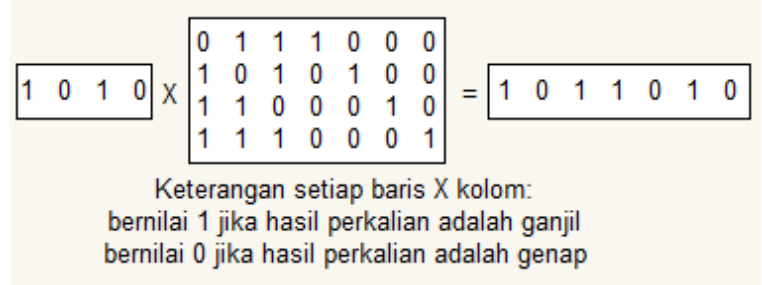

Gambar 4. Enkripsi Menggunakan $(7,4)$ Hamming code

\section{Repetition Code}

Repetition code merupakan model sederhana untuk enkripsi block linear dimana setiap nilai bit dienkripsi sebanyak $\mathrm{n}$ dengan nilai sama. Contoh kasus $(3,1)$ repetition code nilai 1 bit akan dienkripsi menjadi 3 bit dengan mengulang nilai bit yang sama. Sama halnya dengan $(5,1)$ repetition code nilai 1 bit akan dienkripsi menjadi 5 bit dengan mengulang nilai bit yang sama [8]. Tabel 1 menunjukkan enkripsi $(3,1)$ repetition code dan $(5,1)$ repetition code.

Tabel 1. Enkripsi Data Menggunakan Repetition Code

\begin{tabular}{lll}
\hline Repetition code & Pesan Bit & Enkripsi Data \\
\hline \multirow{2}{*}{$(3,1)$} & 00 & 000000 \\
& 01 & 000111 \\
\multirow{2}{*}{$(5,1)$} & 10 & 1111100000 \\
& 11 & 1111111111 \\
\hline
\end{tabular}

\section{Perhitungan Akurasi}

Mean Square Error (MSE) dan Peak Signal to Noise Ratio (PSNR) adalah dua pengukuran yang biasa digunakan untuk membandingkan kualitas kompresi citra. Rasio ini sering digunakan sebagai mengukur kualitas antara citra asli dan citra terwatermark.

Tujuan dari pengukuran PSNR adalah untuk membandingkan kualitas antara citra cover $(C I)$ dan citra terwatermark (TWI). Untuk menghitung nilai $P S N R$, terlebih dahulu harus menghitung nilai MSE. $M S E$ sendiri adalah nilai error kuadrat rata-rata antara CI dan TWI [5]. MSE dapat dihitung dengan rumus:

$M S E=\frac{1}{m * n} \sum_{j=1}^{m} \sum_{j=1}^{n}[I(i, j)-K(i, j)]^{2}$

Keterangan:

I : citra asli

$K$ : citra terwatermark

$m, n:$ dimensi citra

Semakin tinggi nilai PSNR menunjukkan semakin erat kemiripannya antara $C I$ dan TWI. PSNR dapat dihitung dengan rumus: 


$$
P S N R=10 \log _{10}\left(\frac{M A X_{I}^{2}}{M S E}\right)
$$

Keterangan:

$M A X_{I}$ : nilai maksimum dari jenis citra. Untuk citra grayscale $M A X_{I}$ bernilai 255

$M S E$ : nilai MSE yang diperoleh dari persamaan (3)

Tingkat ketahanan antara original watermark dan hasil ekstraksi watermark dapat diukur dengan menghitung nilai Bit Error Rate (BER). BER dapat dihitung dengan rumus :

$$
B E R=\frac{\sum_{i=1}^{\mathbb{N}} \sum_{j=1}^{W} W(i, j) \oplus W^{\prime}(i, j)}{m, n}
$$

Keterangan:

$W(i, j)$ : original watermark

$W^{\prime}(i, j)$ : ekstraksi watermark

$m, n$ : dimensi citra watermark

$\oplus \quad$ : operasi Boolean XOR

Pada keadaan ideal nilai $B E R$ seharusnya bernilai 0 dan maksimal error bernilai 1 [6].

\section{HASIL DAN PEMBAHASAN}

Sistem keamanan citra dengan watermarking menggunakan algoritma hybrid least significant bit diuji dengan beberapa skenario uji coba penyisipan watermark dan ekstraksi watermark. Tabel 2 merupakan skenario uji coba penyisipan watermark dan Tabel 2 merupakan skenario uji coba ekstraksi watermark yang dapat dilihat di Tabel 2 .

Tabel 2. Skenario Uji Coba Penyisipan Watermark

\begin{tabular}{clc}
\hline Skenario & \multicolumn{1}{c}{ Metode LSB } & Level \\
\hline 1 & LSB with Classic Method & $1-8$ \\
2 & LSB with Hamming Code & $1-8$ \\
3 & LSB with Repetition 3 & $1-8$ \\
4 & LSB with Repetition 5 & $1-8$ \\
\hline
\end{tabular}

Tabel 3. Skenario Uji Coba Ekstraksi Watermark

\begin{tabular}{cllr}
\hline Skenario & \multicolumn{1}{c}{ Metode LSB } & Noise & Kompres \\
\hline \multirow{2}{*}{1} & LSB with Classic Method & a) 0.3 a) Format \\
& (level 1-8) & b) $0.5 \quad$ jpg/jpeg \\
2 & LSB with Hamming Code & a) 0.3 a) Format \\
& (level 1-8) & b) $0.5 \quad$ jpg/jpeg \\
3 & LSB with Repetition 3 & a) 0.3 a) Format \\
& (level 1-8) & b) $0.5 \quad$ jpg/jpeg \\
4 & LSB with Repetition 5 & a) 0.3 a) Format \\
(level 1-8) & b) $0.5 \quad$ jpg/jpeg \\
\hline
\end{tabular}

\section{Hasil Uji Coba}

Data uji coba yang digunakan pada penelitian ini adalah 10 citra RGB yang berukuran 512x512 piksel yang didownload dari SIPI Database. Dan citra biner watermark berukuran $64 \times 64$ piksel. Data uji coba dapat dilihat pada Gambar 5.
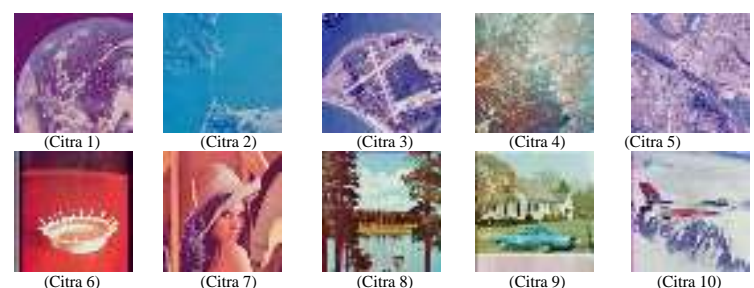

UTM

2014

(Cite wasenat)

\section{Gambar 5. Data Uji Coba}

Pada skenario 1, 2, 3 dan 4 hasil penyisipan watermark dengan metode $L S B$ di level 1 terlihat sangat mencolok citra watermarknya dan berangsur tak terlihat sampai level 8. Hasil perbandingannya dapat dilihat pada Tabel 4.

Tabel 4. Hasil Uji Coba Penyisipan

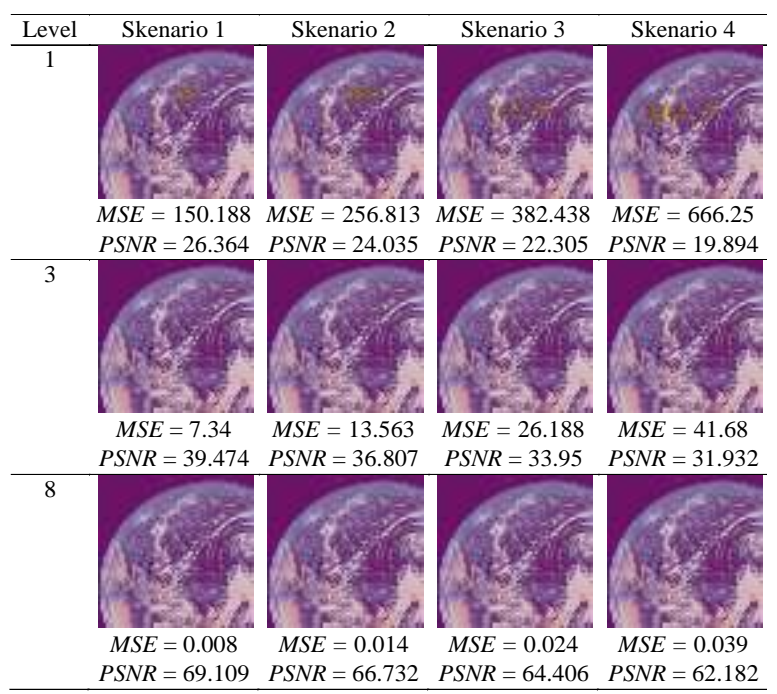

Nilai MSE dan PSNR dapat dihitung dengan membandingkan citra cover dan citra terwatermark. Nilai MSE pada level 1 lebih besar dibandingkan pada level 2 sampai 8. Semakin tinggi nilai MSE menunjukkan semakin tinggi perbedaan yang telah terjadi. Lain halnya dengan PSNR, nilai PSNR menunjukkan tingkat kelayakan citra watermark yang tertanam dari segi penampakan. Pada skenario 2, 3 dan 4 sebelum watermark disisipkan, citra watermark dilakukan enkripsi menggunakan metode hamming dan repetition sehingga ukuran citra berubah menjadi lebih besar. Keadaan ini menyebabkan nilai MSE menjadi tinggi. Rata-rata MSE dan PSNR untuk semua skneario dapat dilihat grafik pada Gambar 6 dan Gambar 7. Hasil ekstraksi watermark dapat dilihat pada Tabel 5 . 
Penulis sengaja memberikan perlakuan noise dan kompresi pada citra terwatermark sebelum dilakukan ekstraksi. Ini bertujuan untuk mengetahui tingkat ketahan citra watermark. BER dihitung untuk mengetahui tingkat error hasil ekstraksi watermark setelah diberi beberapa perlakuan. Dari Tabel 5 di atas terlihat bahwa hasil ekstraksi terbaik dengan perlakuan noise 0,3, noise 0,5 dan kompresi adalah skenario 4 yaitu $L S B$ with Repetition 5. Rata-rata BER untuk noise 0.3, 0.5 dan kompresi jpg/jpeg semua skneario dapat dilihat grafik pada Gambar 8, 9, dan 10).

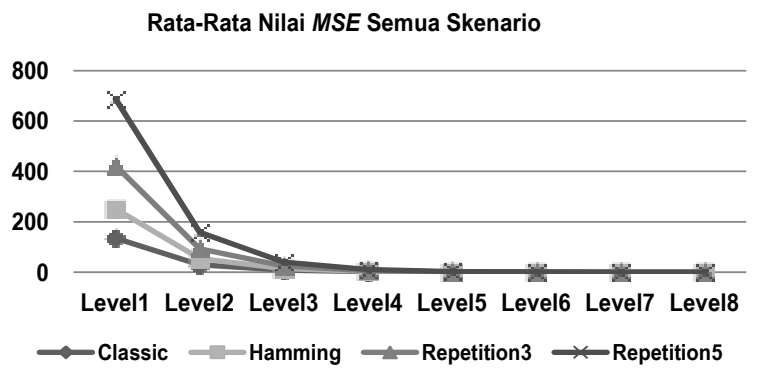

Gambar 6. Diagram Rata-Rata MSE Semua Skenario

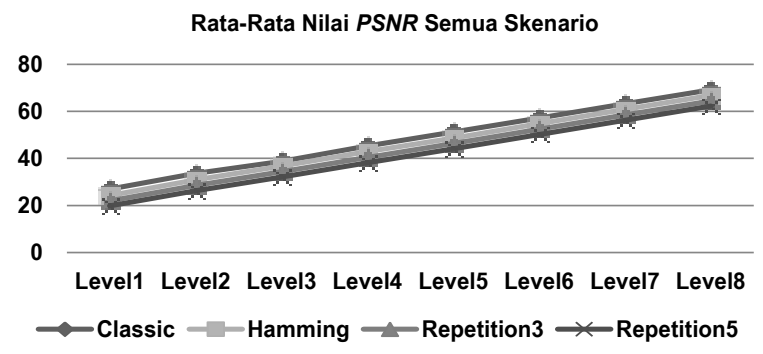

Gambar 7. Diagram Rata-Rata PSNR Semua Skenario

Tabel 5. Hasil Uji Coba Ekstraksi

\begin{tabular}{|c|c|c|c|c|}
\hline Perlakuan & Skenario 1 & Skenario 2 & Skenario 3 & Skenario 4 \\
\hline \multirow[t]{2}{*}{ Noise 0,3} & Thy & & 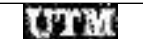 & ब्वि? \\
\hline & $B E R=0.151$ & $B E R=0.134$ & $B E R=0.064$ & $B E R=0.025$ \\
\hline \multirow[t]{3}{*}{ Noise 0,5} & 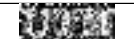 & Bespors & Fras & Bu \\
\hline & $58 \times 6$ & & & \\
\hline & $B E R=0.265$ & $B E R=0.261$ & $B E R=0.161$ & $B E R=0.107$ \\
\hline \multirow{2}{*}{$\begin{array}{l}\text { Kompres } \\
\text { jpg/jpeg }\end{array}$} & 61972 & $\operatorname{TH}$ & 112 & O414 \\
\hline & $B E R=0.0085$ & $B E R=0.0005$ & $B E R=0.00024$ & $B E R=0$ \\
\hline
\end{tabular}

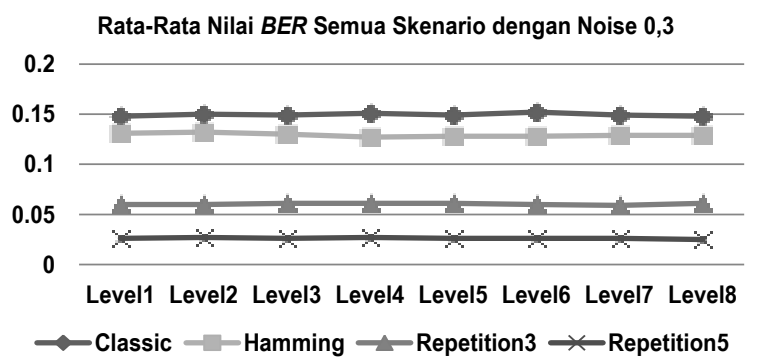

Gambar 8. Diagram Rata-Rata BER Semua Skenario dengan Noise 0.3
Rata-Rata Nilai BER Semua Skenario dengan Noise 0,5

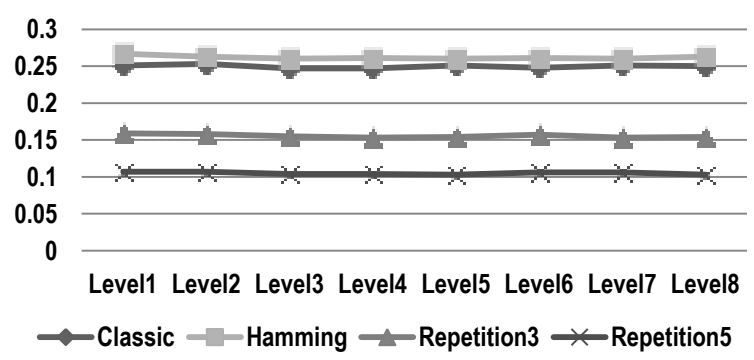

Gambar 9. Diagram Rata-Rata BER Semua Skenario dengan Noise 0,5

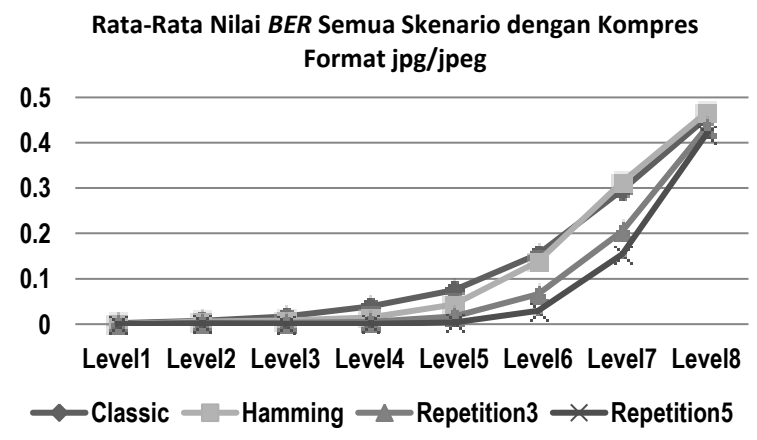

Gambar 10. Diagram Rata-Rata BER Semua Skenario dengan Kompresi Format jpg/jpeg

\section{KESIMPULAN}

Keamanan citra dengan watermarking menggunakan algoritma hybrid least significant bit mampu menyimpan informasi watermark dengan baik. Dengan ditambahnya konsep hybrid yaitu dengan penambahan enkripsi hamming code dan repetition code mampu memperbaiki hasil ekstraksi watermark dibandingkan dengan metode classic atau LSB murni.

Penyisipan watermark pada level yang berbeda mempengaruhi penampakan pada citra hasil. Dengan metode LSB, penyisipan pada level 1 dan 2 masih terlihat secara mencolok watermarknya, dan berangsur tak terlihat dari level 3 sampai level 8 . Keadaan ini memnuhi hakekat watermarking yaitu harus tak terlihat keberadaannya.

Algoritma hybrid least significant bit juga telah terbukti dapat menjaga informasi walaupun telah dilakukan simulasi serangan seperti pemberian noise dan kompresi kualitas jpg/jpeg. Dari percobaan 4 skenario yaitu $L S$ with classic method, LSB with hamming code, $L S B$ with repetition 3 dan $L S B$ with repetition 5 .

\section{DAFTAR PUSTAKA}

[1] Cramer C. 2005. About Digital Watermarking. http://www.willamette.edu/wits/idc/mmcamp/wa termarking.htm. diakses 9 September 2014 jam 23.00 . 
[2] Serrao, C. dan Guimaraes, J. 1999. Protecting Intellectual Proprietary Right through Secure Interactive Contract Negotiation. SpringerVerlag Berlin Heidelberg 1999.

[3] Gulati, K. 2003. Information Hiding Using Fractal Encoding. Thesis for master degree, Mumbai, India.

[4] Titty, T. Steganography: Reversible Data Hiding Methods for Digital Media. Bachelor Project.

[5] Chopra, Deepshikha, Gupta, Preeti., Sanjay, G.B.C., Gupta, Anil. 2012. Lsb Based Digital Image Watermarking For Gray Scale Image. IOSR Journal of Computer Engineering, Vol. 6, Issue 1.

[6] Rohith, Mr S dan Dr. K. N. hari bhat. 2012. A Simple Robust Digital Image Watermarking against Salt and Pepper Noise using Repetition codes. ACEEE Int. J. on Signal \& Image Processing, Vol. 03, No. 01.
[7] Bamatraf, Abdullah., Ibrahim, Rosziati,. Najib, Mohd, M.S. 2011. A New Digital Watermarking Algorithm Using Combination of Least Significant Bit (LSB) and Inverse Bit. Journal of Computing, Vol. 3 Issue 4.

[8] Verma, Rajni dan Archana Tiwari. 2014. Copyright Protection for Watermark Image Using LSB Algorithm in Colored Image. Research India Publications, Vol. 4 No. 5.

[9] Murni, Aniati. 1992. Pengantar Pengolahan Citra. Jakarta. Penerbit: PT Elexmedia Komputindo.

[10] Sitorus, S., Suyanto. 2006. Pengolahan Citra Digital. Medan. Penerbit: USU Press.

[11] Sutoyo. T. 2009. Teori Pengolahan Citra Digital. Yogyakarta. Penerbit: ANDI.

[12] Pengolahan Citra. http:// id.wikipedia.org/wiki/ Pengolahan_citra. Diakses pada 13 Oktober 2014 jam 21.15. 